\title{
Repair of rectus femoris rupture with LARS ligament
}

\author{
Clare Taylor, Rathan Yarlagadda, Jonathan Keenan
}

Trauma and Orthopaedics Department, Derriford Hospital, Plymouth, UK

Correspondence to Miss Clare Taylor, cft199@doctors.org.uk

\begin{abstract}
Summary
The rectus femoris muscle is the most frequently involved quadriceps muscle in strain pathologies. The majority of quadriceps muscle belly injuries can be successfully treated conservatively and even significant tears in the less active and older population, non-operative management is a reasonable option. The authors report the delayed presentation of a 17-year-old male who sustained an injury to his rectus femoris muscle belly while playing football. This young patient did not recover the functional outcome required to get back to running and participating in sport despite 15 months of physiotherapy and non-operative management. Operative treatment using the ligament augmentation and reconstruction system ligament to augment Kessler repair allowed immediate full passive flexion of the knee and an early graduated physiotherapy programme. Our patient was able to return to running and his previous level of sport without any restrictions.
\end{abstract}

\section{BACKGROUND}

The rectus femoris muscle is the most frequently involved quadriceps muscle in strain pathologies, ${ }^{1} 2$ principally because of its two joint function and high percentage of type II muscle fibres, which enable it to produce rapid forceful activity. ${ }^{3} 4$

The rectus femoris is most commonly injured in the acceleration phase of sprinting, explosive jumping, kicking a ball, or when contracting and meeting a resistance (such as two players kicking a football at the same time). Minor tears/strains may only become functionally limiting when performing at physical extremes and it is possible for an athlete to develop compensatory mechanisms which often leads to delayed presentation.

Avulsion type ruptures of the direct head of the rectus femoris from its origin, on the anterior superior iliac spine and distal rectus femoris muscle (quadriceps tendon) ruptures are the most common areas for injury to this muscle and are well reported. Significant injuries to the muscle belly and musculotendinous junction are less common and often treated conservatively.

There are currently no cases in the literature to describe the repair of a intrasubstance tear of the rectus femoris muscle augmented with a synthetic ligament. The LARS (ligament augmentation and reconstruction system) artificial ligament, (UK Distributor, Corin Group PLC, The Corinium Centre, Cirencester, GL7 1YJ, UK) has been previously used and reported for the reconstruction of isolated and multiple knee ligament injuries. ${ }^{5} 6$

We report the delayed presentation of a 17-year-old male who sustained an injury to his rectus femoris muscle belly while playing football and the use of a LARS ligament to augment the repair.

\section{CASE PRESENTATION}

A 17-year-old male presented to orthopaedic out-patients 10 months following an injury sustained while playing football. At the time of injury he developed immediate pain and swelling in the anterior aspect of the thigh and was unable to continue playing. An ultrasound scan confirmed a tear (at least grade 2) in the proximal musculotendinous junction of the rectus femoris. The patient had pain and weakness in the thigh and had been unable to return to any sport.

On examination atrophy of the quadriceps muscle was noted and a $3 \mathrm{~cm}$ palpable gap in the muscle bulk on extending the knee during quadriceps contraction. This was tender to palpation. Clinically the quadriceps power was reduced and there was no neurological deficit.

\section{INVESTIGATIONS}

MRI was arranged which confirmed an incomplete intrasubstance tear of the rectus femoris muscle with a large mass of scar tissue. It was located $15 \mathrm{~cm}$ distal to the level of the femoral head and just distal to the musculotendinous junction. Figure 1 shows a saggital view of the patients thigh with the defect seen anteriorly.

\section{TREATMENT}

Despite 15 months of analgesia and physiotherapy, he had persisting pain over the proximal third of the rectus femoris muscle with weakness and difficulty with both walking and running. He had a full range of knee movement but was only able to straight leg raise for short intervals before fatiguing and developing an extensor lag. Due to his inability to run or participate in sport, the decision was made to proceed with a surgical repair of the rupture.

At surgery, the rectus femoris muscle at the area of the tear was found to be significantly thinned with a $50 \mathrm{~mm}$ palpable defect in the middle third of the muscle belly. The muscle fibres were stretched and there was minimal scar tissue. The scar tissue was excised and the muscle ends freshened. A Kessler stitch using a No 2 vicryl suture was used to approximate the ends of the rupture but did not appear to be strong enough to allow for early mobilisation. A flat $6 \mathrm{~mm}$ wide LARS ligament band was sutured anteriorly for reinforcement using a two vicryl weave suture. The repair was tested throughout the full range of knee flexion, before the closure of the wound. 


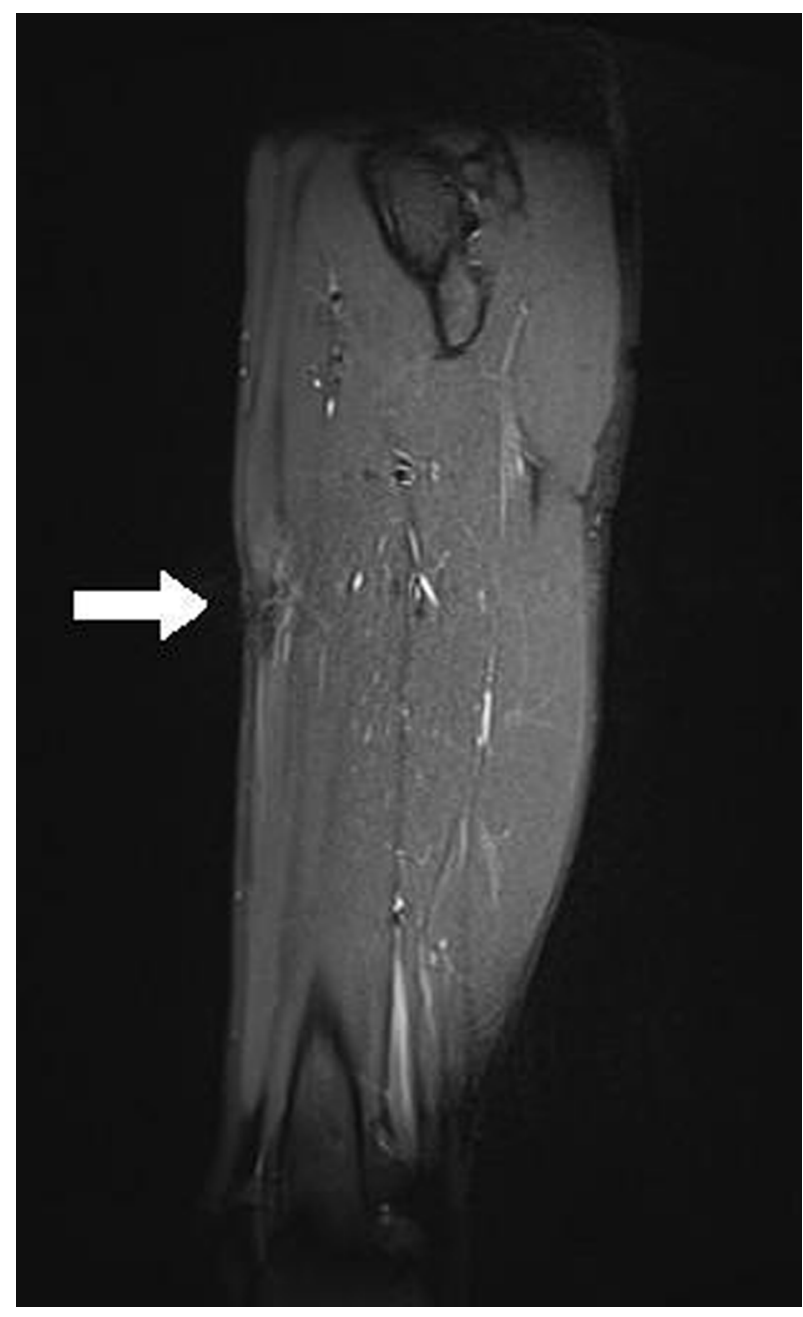

Figure 1 Saggital view of the patients thigh with the defect seen anteriorly.

\section{OUTCOME AND FOLLOW-UP}

In the postoperative period, he was mobilised fully weight bearing in a hinged knee brace with a restricted range of movement of 0-30 degrees for 6 weeks, with passive flexion physiotherapy to 90 degrees out of the brace. At 6 weeks postsurgery he was able to flex the knee to 100 degrees, mobilise short distances without crutches and perform a straight leg raise without fatigue.

At 3 months postsurgery he was walking comfortably without aids and had a full range of movement at the knee with no palpable gap in the muscle. He continued with quadriceps strengthening physiotherapy exercises.

Eight months postoperatively he was pain free, able to walk normal distances and returning to normal activities. He had good quads tone and no palpable gap and was allowed back to training and playing competitive sports including football, he is now playing a full game of football at his preinjury standard without any restrictions.

\section{DISCUSSION}

The rectus femoris muscle is one of the four muscles that make up the quadriceps femoris (anterior compartment) of the thigh. It is the most superficial and anterior of all the quadriceps muscles. Its straight head originates from the anterior superior iliac spine and has a reflected head that blends with the anterior hip joint capsule and iliofemoral ligament just superior to the acetabulum. The two heads form a thick fascial aponeurosis that then blends into the rectus femoris muscle tissue. It crosses two joints and acts as a hip flexor and knee extender. The primary function is that of knee extension. As it crosses the hip joint it also works synergistically with the other hip flexors to generate hip flexion and works to stabilise the pelvis on the weight-bearing femur.

The mechanism of injury to the muscle usually involves both eccentric and explosive muscle contraction, while playing football this commonly occurs due to the forceful contraction of the quadriceps to extend the knee and flex the hip when kicking a ball. ${ }^{7}$

These injuries are uncommon and often present late and so it is important to maintain a level of clinical suspicion in patients that have chronic thigh pain following an injury involving one of the above mechanisms. Rectus femoris muscle belly injuries differ from the more frequent distal rectus femoris muscle injuries (quadriceps tendon) by their presentation and clinical examination. They typically present late, with an anterior thigh mass and chronic pain. When compared with the contra lateral limb asymmetry is often noted. ${ }^{2}$ There is little in the literature concerning these more proximal muscle injuries.

On review of the literature we found only one report by Straw et al on surgical repair for a chronic rupture at the proximal musculotendinous junction with direct suture repair using No 2 Ethibond?

There are no documented reports of a LARS ligament being used to augment the repair. The LARS ligament is a system of synthetic (industrial strength polyester) fibres designed to mimic the mechanical and anatomical properties of human ligament fibres. The fibres are orientated to resist fatigue especially in flexion and have biocompatible properties to human tissue. This results in fibroblastic ingrowth strengthening of the overall structure. ${ }^{8}$

The majority of quadriceps muscle belly injuries can be successfully treated conservatively and even with significant tears in the less active and older population, nonoperative management is a reasonable option. This young patient did not recover the functional outcome required to get back to running and participating in sport despite 15 months of physiotherapy and non-operative management. Operative treatment using the LARS ligament to reinforce a Kessler repair allowed immediate full passive flexion of the knee and with an early graduated physiotherapy programme allowed our patient to return to running and his previous level of sport without any restrictions.

\section{Learning points}

- The rectus femoris muscle is the most frequently involved muscle in strain pathologies, commonly injured during acceleration or kicking actions.

- Intrasubstance injuries can usually be treated conservatively.

- If intrasubstance injuries remain functionally limiting and produce pain and weakness surgical intervention should be considered.

- Patients can return to full function postsurgical repair, even with delayed presentation. 


\section{BMJ Case Reports}

Competing interests None.

Patient consent Obtained.

\section{REFERENCES}

1. Speer KP, Lohnes J, Garrett WEJrRadiographic imaging of muscle strain injury. Am J Sports Med 1993;21:89-95; discussion 96.

2. Hughes C4thHasselman CT, Best TM, et al. Incomplete, intrasubstance strain injuries of the rectus femoris muscle. Am J Sports Med 1995;23:500-6.

3. Garrett WEJrCaliff JC, Bassett FH3rd. Histochemical correlates of hamstring injuries. Am J Sports Med 1984;12:98-103.

4. Garrett WEJrRich FR, Nikolaou PK, et al. Computed tomography of hamstring muscle strains. Med Sci Sports Exerc 1989;21:506-14.
5. Lavoie P, Fletcher J, Duval N. Patient satisfaction needs as related to knee stability and objective findings after ACL reconstruction using the LARS artificial ligament. Knee 2000;7:157-63.

6. Nau T, Lavoie P, Duval N. A new generation of artificial ligaments in reconstruction of the anterior cruciate ligament. Two-year follow-up of a randomised trial. J Bone Joint Surg Br 2002;84:356-60.

7. Straw R, Colclough K, Geutjens G. Surgical repair of a chronic rupture of the rectus femoris muscle at the proximal musculotendinous junction in a soccer player. Br J Sports Med 2003;37:182-4.

8. Corin (2009) Ligament Augmentation and Reconstruction System Brochure. 1-2. http://www.coringroup.com/medical_professionals/products/ligaments/ introduction (accessed 10 May 2011)

This pdf has been created automatically from the final edited text and images.

Copyright 2012 BMJ Publishing Group. All rights reserved. For permission to reuse any of this content visit

http://group.bmj.com/group/rights-licensing/permissions.

BMJ Case Report Fellows may re-use this article for personal use and teaching without any further permission.

Please cite this article as follows (you will need to access the article online to obtain the date of publication).

Taylor C, Yarlagadda R, Keenan J. Repair of rectus femoris rupture with LARS ligament. BMJ Case Reports 2012;10.1136/bcr.06.2011.4359, Published XXX

Become a Fellow of BMJ Case Reports today and you can:

- Submit as many cases as you like

- Enjoy fast sympathetic peer review and rapid publication of accepted articles

- Access all the published articles

- Re-use any of the published material for personal use and teaching without further permission

For information on Institutional Fellowships contact consortiasales@bmjgroup.com

Visit casereports.bmj.com for more articles like this and to become a Fellow

Keep up to date with all published cases by signing up for an alert (all we need is your email address) http://casereports.bmj.com/cgi/alerts/etoc 